\title{
Medidas de economía de bienestar que destruyen empleo en la economía digital ${ }^{*}$
}

\author{
Recibido: 27 de agosto de 2020 - Aprobado: 2 de octubre de 2020 \\ https://doi.org/10.22395/seec.v23n55a4
}

Antonio Sánchez-Bayón ${ }^{* *}$

\section{RESUMEN}

Este es un estudio crítico y comparado de Economía Política, desde el enfoque de Economía Global y Gestión Intercultural, en el que se revisan fundamentos y se retiran velos de confusión. Se parte de la crisis de la COVID-19, que ha resultado un acelerador en la transición digital y la transformación laboral. Durante la crisis ha crecido la polarización entre dos tipos de colaboradores, los knowmads y los freeriders, quienes carecen aún de adecuada regulación propia, por lo que se pretende su encaje en categorías obsoletas. Desde los Gobiernos, se están aplicando medidas económicas tradicionales (proteccionistas), como el salario mínimo, agravándose el problema (con un efecto negativo en cascada). Con este estudio, se pretende alertar sobre el riesgo de colapso abrupto de la caduca economía de bienestar estatal, de modo que la transición digital y sus relaciones laborales no se frenen, sino que se realicen a tiempo y de manera pacífica.

\section{PALABRAS CLAVE}

Economía de bienestar estatal; economía de bienestar personal; transición digital; relaciones laborales; salario mínimo interprofesional; inflación; deflación.

\section{CLASIFICACIÓN JEL}

A14; B5; I31; J8; K0; N3; O15.

\section{CONTENIDO}

Introducción; 1. La crisis COVID-19 y confusión de confusiones; 2. Transición digital y transformaciones laborales: emergencia de knowmads \& freeriders; 3. Evaluación de medidas adoptadas con la crisis COVID-19: estudio de caso de SMI y sus implicaciones económico-laborales; 4. Discusión y conclusiones; ganadores y perdedores; Bibliografía.

- Texto parte de la tesis doctoral en Economía y con respaldo del grupo de investigación GESCE-URJC.

** Doctor y licenciado en Derecho, Universidad Complutense de Madrid, Madrid, España. Doctor en Teología, Universidad de Murcia, Murcia, España. Doctor en Humanidades, Universidad de Valladolid, Valladolid, España. Doctor en Filosofía, Universidad Complutense de Madrid, Madrid, España. Doctorando en Economía, Universidad de Valladolid, Valladolid, España. Doctorando en Economía, Universidad Complutense de Madrid, Madrid, España. Profesor de Economía Aplicada, Universidad Rey Juan Carlos, Campus Vicálvaro, Paseo de Artilleros s/n, 28032 Madrid, España. E-mail: antonio.sbayon@urjc.es. Orcid: https://orcid.org/0000-0003-4855-8356 


\section{ECONOMIC WELFARE MEASURES THAT DESTROY EMPLOYMENTS IN THE DIGITAL ECONOMY}

\section{ABSTRACT}

This is a critical and comparative study of Political Economy, made from Global Economy and Inter-cultural Management approaches, in which the fundaments are reviewed and veils of confusion are taken away. This study starts off from the COVID-19 crisis, which has been an accelerator of the digital transition and the work transformation. The polarization between the two types of collaborators, the knowmadsy and the freeriders, has grown and are still lacking off an adequate regulation, thus pretending to make them fit in obsolete categories. Some traditional (protectionist) economic measures are being applied by Governments like the minimum wage, aggravating the problem (with a negative cascading effect). With this study, the research pretends to raise an alert on the risk of an abrupt collapse of the deciduous Welfare State economy, so that the digital transition and its work relationships are not stopped but carried out timely and peacefully.

\section{KEY-WORDS}

Welfare State Economy; Personal Welfare Economy; Digital Transition; Work Relationships; Inter-professional minimum wage; Inflation; Deflation.

\section{JEL CODE}

$\mathrm{A} 14 ; \mathrm{B} 5 ; \mathrm{I31} ; \mathrm{J8} ; \mathrm{K} 0 ; \mathrm{N} 3 ; \mathrm{O} 15$.

\section{CONTENTS}

Introduction; 1. The COVID-19 crisis and the confusion of all confusions; 2. Digital transition and work transformations: the emergence of the knowmads $\varepsilon$ freeriders; 3 . Assessment of the measures adopted with the COVID-19 crisis: a case study of the SMI and its work-economy implications; 4 . Discussion and conclusion; winners and losers; Bibliography.

\section{MEDIDAS DE ECONOMIA DE BEM-ESTAR QUE ACABAM COM EMPREGOS NA ECONOMIA DIGITAL}

\section{RESUMO}

Este é um estudo crítico e comparativo da economia política, a partir da abordagem da economia global e da gestão intercultural, em que os fundamentos são revisados e os elementos pouco claros são removidos. Partese da crise da covid-19, que tem sido um acelerador na transição digital e na transformação de empregos. Durante a crise, cresceu a polarização entre dois tipos de colaboradores, os knowmads e os freeriders, que ainda carecem de regulamentação própria adequada e, por isso, terminaram sendo classificados em categorias que já estão obsoletas. Os governos estão aplicando medidas econômicas tradicionais (protecionistas), como o salário mínimo, agravando o problema (com efeito cascata negativo). Com este estudo, pretende-se alertar para o risco de um colapso abrupto da defasada economia previdenciária estatal para que a transição digital e as relações de trabalho não sejam afetadas, mas realizadas no tempo adequado e de forma pacífica.

\section{PALAVRAS-CHAVE}

Economia de bem-estar do Estado; Economia de bem-estar pessoal; Transição digital; Relações de trabalho; Salário mínimo interprofissional; Inflação; Deflação.

\section{CLASSIFICAÇÃO JEL}

$\mathrm{A} 14 ; \mathrm{B} 5 ; \mathrm{I31} ; \mathrm{J8} ; \mathrm{K} 0 ; \mathrm{N} 3 ; \mathrm{O} 15$.

\section{CONTEÚDO}

Introdução; 1. A crise de covid-19 e a confusão das confusões; 2. Transição digital e transformações de trabalho: emergência de knowmads $\varepsilon$ freeriders; 3 . Avaliação das medidas adotadas com a crise de covid-19: estudo de caso da SMI e suas implicações econômico-trabalhistas; 4. Discussão e conclusões; Vencedores e perdedores; Bibliografia. 


\section{INTRODUCCIÓN}

En el mundo cada vez están más presentes, y de manera acelerada, las crisis y transformaciones consiguientes, dada la transición entre épocas (Manzanero et al, 2014; Valero et al, 2018): son las crisis de un caduco mundo rígido (dominado por el Estado-nación y la gestión burocrática replicante), dando paso a la emergencia de un mundo flexible, tendente a la aldea global (gracias a la gobernanza de las organizaciones internacionales, Andreu et al, 2019; Sánchez-Bayón, 2019a). Como marco de dicha transformación, actualmente se está en la posglobalización (SánchezBayón, 2017a): se trata de un tiempo breve de convergencia mundial, iniciado en 2008 con el fin de la globalización (debido a la crisis de valores) y vigente hasta el año 2030 (llamado Horizonte 2030 o H2030: fecha de vencimiento de los confluyentes programas transformadores de organizaciones internacionales, v.g. ODS, Global Compact \& Future of Work de ONU, Green Deal de UE). H2030 supone un punto de no-retorno (al producirse la singularidad tecnológica y humana). Aquellos países y empresas que se hayan alineado, estarán más cerca de la sociedad del conocimiento-SC y su economía1. Quienes se queden fuera del proceso de convergencia, correrán el riesgo de volverse parte de una dependiente sociedad masa de consumo global (Sánchez-Bayón, 2016a).

En el marco dado, los cambios no son ni buenos ni malos, solo inevitables y hay que conocerlos, para saber gestionarlos: por no querer renunciar a un paradigma breve, como el de economía de bienestar estatal (EB) y su falsa seguridad (v.g. trabajo indefinido a tiempo completo en una misma compañía y con salario estable y mejorable por antigüedad, no por productividad); entonces, se entenderá que al inicio de la globalización, se calificara el mundo de VUCA (acrónimo de volátil, incierto, complejo y acelerado, como estableciera en los años 90 el Ejército estadounidense y popularizara la Univ. Harvard); con las crisis de la década de 2.000 (desde las .com hasta la de valores citada), se pasó a hablar de un mundo frágil (considerado así por ser de riesgo, líquido, corrosivo, etc., al caducar las instituciones y no cristalizar las nuevas, con una mayor incertidumbre en las interacciones, Manzanero et al, 2014; Sánchez-Bayón, 2018); en la posglobalización, gracias a las tecnologías del aprendizaje y conocimiento-TAC, se invita a pensar en términos de antifrágil (Taleb, 2012) y, finalmente, ágil (Dupont, 2019). En la economía digital (ED), disminuirán los trabajadores (aparecidos con la decimonónica $2^{\circ}$ rev. industrial, en la que se necesitaban muchos asalariados poco cualificados para abastecer las fábricas); en su lugar aparecerán los colaboradores, con más tiempo y libertad, gracias al valor de su conocimiento. Como adelanto de los cambios paradigmáticos, véase la tabla 1. Antes de continuar,

Como último estadio de la economía digital, tras la fase gig (que comprende la economía colaborativa y circular, más la autónoma y naranja, Sánchez-Bayón, 2019b y c) y la fase wellbeing economics (que combina talentismo, gestión de la felicidad, etc., Sánchez-Bayón, 2019d y e). 
solo cuestionar algo TAC: cinstalaría software obsoleto en su móvil o ingeriría comida caducada? Entonces, ¿por qué seguimos consumiendo conocimiento desfasado y alejado de la realidad? Así solo causamos indefensión aprendida a las próximas generaciones, en vez de dotarles de herramientas para vivir mejor.

Tabla 1. Revelaciones de cambios paradigmáticos y relaciones laborales en las empresas

\begin{tabular}{ll}
\hline \multicolumn{1}{c}{ Viejo Paradigma (EB) } & \multicolumn{1}{c}{ Nuevo Paradigma (ED: gig a WB) } \\
\hline Economía industrial y material (mecanicista) & Econ. conocimiento y experiencias (cuántica) \\
\hline $\begin{array}{l}\text { Masculino (jerárquico, competitivo) } \\
\text { Tangible y escaso (fabrica/oficina, bienes) }\end{array}$ & $\begin{array}{l}\text { Femenino (holocrático, comunicativo) } \\
\text { Virtual y abundante (móvil, conexiones, experiencias) }\end{array}$ \\
\hline $\begin{array}{l}\text { Cosificación (dinero, horas extra, titulación, } \\
\text { orientación a resultados: medidas higiénicas) }\end{array}$ & $\begin{array}{l}\text { Humanización (bienestar, ocio, talento, orientación a } \\
\text { personas: medidas motivacionales) }\end{array}$ \\
\hline $\begin{array}{l}\text { Trabajadores: uniformes, Sector secundario, } \\
\text { subordinación (asalariado, heterónomo) }\end{array}$ & $\begin{array}{l}\text { Colaboradores: diversos, Sector terciario y cuaterna- } \\
\text { rio, elección (autonomía, responsabilidad) }\end{array}$ \\
\hline $\begin{array}{l}\text { Sistema cerrado: rígido y pobre (burocrático, } \\
\text { para un puesto) }\end{array}$ & $\begin{array}{l}\text { Sistema abierto (autopoiético): flexible y abundante } \\
\text { (creativo y cambiante) }\end{array}$ \\
\hline $\begin{array}{l}\text { Competición (repetición —reparto cociente-- } \\
\text { concentración empresarial/multinac.: raíles) }\end{array}$ & $\begin{array}{l}\text { Colaboración (innovación -modelo Westminister: }{ }^{\circ} \\
\text { lo gana todo-, coworking: mundo elefantes-hormigas) }\end{array}$ \\
\hline $\begin{array}{l}\text { Estudio macroeconómico y econométrico: } \\
\text { principal agente SP }\end{array}$ & $\begin{array}{l}\text { Estudio microecon. y CCM: principal agente empren- } \\
\text { dedor }\end{array}$ \\
\hline $\begin{array}{l}\text { Relaciones simples y unidireccionales (B2C), } \\
\text { mono-negocio L/Py FPP limitada (costes fijos) }\end{array}$ & $\begin{array}{l}\text { Relaciones complejas y múltiples (B2C, B2B, P2P, etc.), } \\
\text { multi-negocio C/P, FPP variable (heurística) }\end{array}$ \\
\hline $\begin{array}{l}\text { Átomo (tamaño y localización de oficinas, } \\
\text { stock almacenes, no empleados) }\end{array}$ & $\begin{array}{l}\text { Bit (velocidad y ewc, bajo demanda, talento, colabo- } \\
\text { radores) }\end{array}$ \\
\hline $\begin{array}{l}\text { Manufactura (valor añadido por transformación } \\
\text { de bienes) }\end{array}$ & $\begin{array}{l}\text { Mentefactura (servicio cualificado —concepto/ } \\
\text { experiencias- y mayor valor) }\end{array}$ \\
\hline $\begin{array}{l}\text { Gerencia de control (corregir y monopolizar } \\
\text { información y conocimiento) }\end{array}$ & $\begin{array}{l}\text { Gerencia de delegación/coach (reglas y compartir } \\
\text { información y conoc.) }\end{array}$ \\
\hline $\begin{array}{l}\text { Resultados por presión y decisiones por temor } \\
\text { (despido) }\end{array}$ & $\begin{array}{l}\text { Resultados. por proyectos y logros, y decisiones por } \\
\text { amor (a lo que hago, con quién, m-v-v) }\end{array}$ \\
\hline
\end{tabular}

Fuente: elaboración propia.

Una acepción coloquial de locura es hacer siempre lo mismo esperando resultados distintos; por tanto, ha de repensarse todo, revisándose los fundamentos de cada esfera social (Derecho, Política, Economía, etc.) y, en especial aquí, los principios económicos (con sus implicaciones político-jurídicas). Dichos principios fueron ya fijados por la escuela clásica, neoclásica y austríacos, siendo adaptados por Pigou (1920) y Keynes (1936), junto con sus seguidores (VV.AA., 1981), formando el mainstream o pensamiento dominante del modelo de EB (confundiéndose —interesadamente- 
política y economía, pese a ser esferas sociales distintas y con reglas e instituciones diferentes). Por tanto, entre los fundamentos a revisar (previa revelación o retirada de velos de confusión, Sánchez-Bayón, 2017a), y desde el enfoque de Global Economics \& Cross-Cultural Management-GEGCCM (Escuelas de agua dulce y Escuelas de Negocios$^{2}$, así como en Facultades de Economía con disciplinas duales, tipo Economía Aplica, al acoger hoy Economía Política y Principios de Economía)³, cabe destacar, por su aplicación a las relaciones laborales:

- (Re)pensar la economía no solo en términos de renta (PIB), sino de bienestar (incluso, de felicidad, como postularan los clásicos, como Bentham o Stuart Mill, Rojas, 2014). Se trata de dejar de estudiar la economía mediáticamente (cómo producimos y distribuimos para lograr más riqueza), para hacerlo de manera finalista (por qué producimos y distribuimos; nos proporciona mayor satisfacción y felicidad, Caravaggio, 2016). Recuérdese: no se trabaja para lograr una renta, sino que dicha renta ofrezca tiempo y libertad (luego, también hay que repensar el trabajo, pues no es un fin, sino un medio, ergo no cabe una realización laboral, aunque sí motivacional, Sánchez-Bayón, 2019d).

- (Re)pensar los recursos y factores de producción distintos a TTK (acrónimo de tierra, trabajo y capital), para prestar mayor atención a TIC-TAC (tecnologías de la información y comunicación, y las ya aludidas tecnologías del aprendizaje y conocimiento), de modo que tampoco se centre la atención en bienes y servicios, sino en experiencias (orientadas a mejorar satisfacción y bienestar, pues no se trata ya de adquirir, sino de tener acceso y compartirlo, Rifkin, 2000).

2 Sobre las Fresh/Sweat-water School, son las universidades del interior y grandes lagos: Chicago, Northwestern, Michigan, Minneapolis, Carnegie Mellon, Pittsburgh, Minnesota, Cornell, Rochester, etc.; llamadas así en contraposición a las de agua salada (las de las costas: Harvard, MIT, California, Standford, etc.), como son las referentes del mainstream keynesiano y post-keynesiano. En cuanto a las B-Schools, Sánchez-Bayón et al, 2019).

3 GEECCM y su giro hermenéutico: para comprender la transición digital y la transformación de la cultura empresarial y profesional en curso, que explique mejor la fase de la economía gig (que comprende — como se ha señalado - las manifestaciones de ECC, EA y EN), y su transición al nuevo estadio: wellbeing economics (o economía de auténtico bienestar — no estatal, sino personal y de la humanidad en su conjunto-, que comprende a su vez manifestaciones como el talentismo y la economía de la felicidad). Ello ha sido posible desde planteamientos heterodoxos y praxeológicos (basados en la experiencia de las organizaciones líderes en dichos procesos de transición y transformación, v.g. Global Compact-ONU, Wellbeing Allianze-WEF, GPTW, Merco). Así, se recuperar el espíritu original de la propia economía, cuando los clásicos (v.g. Bentham, Stuart Mill, Malthus) se cuestionaban la riqueza y bienestar, más allá de la mera medición de la producción nacional, para responder también al nivel de satisfacción ciudadana con el progreso alcanzado (cód. JEL: I31 Bienestar general; Nivel de vida; Calidad de vida; Felicidad). Entre los Premios Nobel de Economía referentes en el giro hermenéutico (de la macro-econometría a lo micro interconectado con otras CC.SS.): Hayek \& Myrdal (con su acción humana, galardonados en 1974), Simon (con su racionalidad limitada, 1978), Buchanan (toma de decisiones, 1986), Becker (comportamiento humano, 1992), Nash et al (teoría de juegos, 94), Sen (capacidades, bienestar y desarrollo, 98), Akerlof et al (información asimétrica y economía de identidad, 01), Kahneman \& Smith (toma de decisiones y bienestar, 02), más Schelling et al (05), Krugman (08), Shiller (13), Deaton (15), Thaler (17), et al. 
- En tal sentido, el trabajo (surgido tras la $1^{\circ}$ rev. industrial y tipificado tras la 20, Sánchez-Bayón, 2019e) ${ }^{4}$, iría desapareciendo, dando paso al regreso del profesional y los colaboradores talentosos (así se fomentará la autonomía y creatividad, con mayor ganancia: es más preciado el talento autónomo que la hora subordinada). Es por ello que este estudio centra la atención en dos figuras cada vez más polarizadas, como son los knowmads y los freeriders (vid. supra).

- (Re)pensar los agentes económicos, más allá de las empresas y del Estado (o, mejor dicho, Sector Público), para atender al híbrido de las corporaciones, y no en términos de ficciones jurídicas (como son las personas jurídicas, también conocidas como morales o sociales), ni de meros sistemas de producción (como lo hace la economía de bienestar estatal); más bien, conviene su consideración como organizaciones sociales donde se lideran personas y proyectos (Andreu et al, 2019). Por tanto, dichas organizaciones han de ser de pleno sentido, por lo que las interacciones que se den en y desde ellas han de ser conforme a una misión, visión y valores compartidos e integrados. De ahí, se llega al compromiso con la RSC 3.0, que permite constatar que las organizaciones poseen pleno sentido y están orientadas a un mayor bienestar (tal como requiere el nuevo estadio de la economía digital, como es la economía de auténtico bienestar o wellbeing economics); es por ello que, en la actualidad, se insiste en las empresas sociales (Díaz-Fonseca et al, 2012).

- Otro agente que cobra protagonismo es el emprendedor (Navajas et al, 2016), quien está llamado a crear redes de colaboración y equipos profesionales para afrontar los complejos problemas de hoy en día.

4 Sirva como síntesis de las revoluciones industriales y su impacto económico: a) $1^{\circ}$ rev. industrial (aprox. 17501870, en Europa Atlántica): gracias al carbón y la máquina de vapor, se pasa del campo a los talleres urbanos (siendo uno de sus sectores de referencia el textil), con contratos civiles de arrendamiento de servicios (por jornadas y prestaciones pactadas); frena su avance los vestigios de estamentos y gremios; b) $2^{\circ}$ rev. industrial (aprox. 1880-1950, en Europa, EE.UU. y Japón): gracias al petróleo, la electricidad y a la cadena de montaje, se pasa de los talleres a las fábricas (siendo uno de sus principales sectores el automovilístico), con contratos de trabajo propiamente (bajo un régimen ius laboral tuitivo); altera su avance (con aceleraciones y recesiones) las guerras y las intervenciones estatales; c) $3^{\circ}$ rev. industrial (aprox. 1960-2008, en Occidente): gracias a la informática y la robotización, más la energía nuclear y renovables, se pasa de fábricas a sedes tecno-burocráticas centralizadas y módulos de producción y ventas deslocalizados, más la eclosión de malls o centros comerciales, con diversidad de relaciones laborales y empleabilidad (contratos civiles y mercantiles, laborales, funcionariales, etc.). Sigue alterando su avance las intervenciones estatales (es la era dorada de la economía de bienestar estatal); d) $4^{\circ}$ rev. industrial y transición digital (aprox. 2008-2030, mundial): gracias a internet, la programación (especialmente, blockchain desde 2009) y el móvil (como oficina integrada), es la era de las redes sociales, las apps \& everywhere commerce-ewc o comercialización continua virtual, dándose el regreso del profesional (knowmads v. freeriders), quien puede ser comisionista, facturador, afiliado, etc. (surgen nuevas fórmulas de regulación de relaciones laborales mixtas, v.g. click-pay, flexecurity, part-time jobs mix). También es el periodo de la emergencia de smart-contracts \& DAO (contratos inteligentes, como códigos en la nube, cuyas partes son inteligencias artificiales, que operan desde Bolsa hasta la conducción sin chofer). De tal modo, no solo se transita a la economía digital-ED en su fase gig o de bolos, sino que además se va esbozando el nuevo estadio del capitalismo, como es el talentismo (vid. supra). 
- (Re)pensar las medidas económico-sociales a adoptar para paliar y suavizar las transformaciones anunciadas al inicio - se insiste, no son fallos de mercado, sino cambios paradigmáticos_-; dichas transformaciones se han intensificado con la crisis de la COVID-19 (v.g. teletrabajo). Resulta que, si se insiste en un proteccionismo de $\mathrm{EB}^{5}$, solo se va a conseguir acelerar su propia extinción: mejor que resistirse al cambio (endeudándose para ello, con medidas como el salario mínimo), quizá convenga conocer mejor cómo opera tanta transformación y transición, de modo que quepa una regulación adecuada (y, con segurirdad novedosa, no adaptando sin más la anterior: nuevo juego, nuevas reglas).

Por tanto, aunque podrían esbozarse otras muchas cuestiones de fundamentos a (re)pensar, baste con los puntos propuestos, como partida, para intensificarse en el último.

\section{LA CRISIS COVID-19 Y CONFUSIÓN DE CONFUSIONES}

La crisis COVID-19, puesta en contexto, solo es una expresión agravada de otra mayor en curso: la crisis de valores de 2008, era heredera de la de derivados de 1998 y fue aplacada vía déficit y endeudamiento (v.g. en la Eurozona, pese al pacto de estabilidad, que impedía tener una deuda superior al $60 \%$, en cambio, la mayor parte se acercó al 80 \%, dándose la paradoja de que el resto de Estados de la Unión Europea-UE, llegaron a tener una deuda inferior). El problema es que la deuda hay que pagarla pasada una década, de ahí que hacia el 2018 comenzara una desaceleración, que poco a poco se convirtiera en recesión (al acumular trimestres consecutivos de crecimiento negativo). Para evitar sus efectos, tuvieron lugar las guerras comerciales (EE.UU. v. China, EE.UU. v. UE, etc.). Finalmente, se produjo la pandemia de la COVID-19, con su economía de guerra y gran confinamiento (VV.AA., 2020). Con el actual escenario, próximo al de desglobalización (anunciado ya por el Secretario Gral. de ONU en 2020), no solo se ha limitado el comercio internacional, ha aumentado el proteccionismo, sino que el endeudamiento es mayor (incluso, la Comisión Europea, el 20 de marzo de 2020, aprobó la activación de la cláusula de incumplimiento de pacto de estabilidad y crecimiento). De tal suerte, hay países que se endeudarán solo para superar la crisis sanitaria y económica (procurando volver a los planteamientos de H2030); y otros, que pretenderán ahondar en la

\footnotetext{
Secretario Gral. ONU, António Guterres: "falta de liderazgo mundial... desglobalización" (Guterres, URL: https://www.un.org/sg/en/content/sg/declarations-and-messages. Revista "Economistas", URL: https://www. ibercampus.es/tendencia-a-la-desglobalizacion-de-comercio-capitales-y-personas-segun-economistas-39056. htm). Características de la desglobalización: control fronterizo; regulación local restrictiva de transacciones (comercio y trabajo); intensificación de inspecciones y sanciones; nacionalización de empresas de distribución y sus canales; aumento de presión fiscal, etc.
} 
desglobalización (de vuelta a un sistema mercantil, en el mejor de los casos —si regresan a un patrón oro-).

En el contexto de la crisis de la COVID-19, se ha avanzado mucho en la transición digital para los consumidores (o sea, por el lado de la demanda, Deloitte, 2020); pero falta por hacerse por el lado de la oferta, en especial, para trabajadores y empresas. Aquí se esboza un mínimo análisis DAFO (debilidades, amenazas, fortalezas y oportunidades) de los nuevos tipos de relaciones laborales que están emergiendo (se recuerda que no son definitivas, sino transitoria, por corresponderse con una fase, como es la gig, en tránsito a la de wellbeing economics, vid. siguiente epígrafe).

En cuanto a la mención en el rótulo de confusión de confusiones (Sánchez-Bayón, $2019 \mathrm{~g})$, se alude así al que puede considerarse como el proto-manual de finanzas (sobre todo, del mercado de valores, y algo de banca), escrito hacia el año 1688 por José de la Vega, un judío español emigrado a Ámsterdam (cerca de 130 años, antes de que otro sefardí, también emigrado a los Países Bajos, escribiera su famoso y fundacional Principios de Economía Política y Tributación, Ricardo, 1817). Demostró tal pericia para las finanzas, que pudo legarlo a la postre en un ágil diálogo (al estilo platónico) entre un filósofo agudo, un mercader discreto y un accionista erudito (tal como retrata el subtítulo de la obra, De la Vega, 1688) ${ }^{6}$. Dicho proto-manual pone de manifiesto lo arriesgado que es jugar en bolsa sin conocer y aplicar bien sus reglas. Mutatis mutandis, cabe llamar la atención a todos aquellos Gobiernos y sus asesores que siguen aplicando recetas ya caducas de EB (pensadas en el periodo de entreguerras y solo operativas tras la $2^{\circ}$ Guerra Mundial, para reactivar las maltrechas economías europeas, pero que afínales de los años 70, nórdicos y anglosajones empezaron a abandonar (pasando de modelos ideológicos a gestión para volver a crecer, v.g. doing business index del Banco Mundial) $)^{7}$. Pues bien, se asiste hoy a la confusión de confusiones, que esta vez (para este texto), se presta atención en el caso del salario mínimo interprofesional (SMI): ¿ por qué una supuesta buena idea de unos pocos puede acarrear tantos problemas a tanta gente? Dicho de otro modo, ¿por qué subir el SMI indiscriminadamente causa una aceleración del desempleo y un despunte de la inflación, reduciéndose la recaudación fiscal y debilitándose el poder adquisitivo de todos, además de intensificarse la extinción de las coberturas del Estado de bienestar? Como se verá, al final, el más perjudicado es el asalariado

6 El título original: Confusión de confusiones: diálogos curiosos entre un philosopho agudo, un mercader discreto, y un accionista erudito, describiendo el negocio de las acciones, su origen, su ethimologia, su realidad, su juego, y su enredo (Taller David de Castro: Ámsterdam, 1688).

7 Tras las crisis energéticas y laborales de principios de los años 70, difícilmente superables a lo largo de dicha época, por la rigidez regulatoria y de mercados, así como por el lastre del endeudamiento acumulado, tanto Reino Unido, Australia, Nueva Zelanda y Canadá, sobre todo, cambiaron su modelo económico. Fue entonces cuando liberales y laboristas renunciaron a los postulados ideológicos, para centrarse en la gestión. 
poco cualificado al que se pretendía proteger (v.g. servicio doméstico). Yotro perjuicio severo es la destrucción del empleo en ED, al impedir su desarrollo.

\section{TRANSICIÓN DIGITAL Y TRANSFORMACIONES LABORALES: EMERGENCIA DE KNOWMADS \& FREERIDERS}

Gracias al enfoque de GE\&CCM, es posible realizar a continuación un análisis sociocultural holístico de las relaciones laborales y organizacionales, atendiéndose al tránsito de un viejo modelo rígido y burocrático de RR.HH. (en el seno de EB), a otro nuevo, flexible y creativo de auténtico bienestar (según el talentismo y la gestión felicidad de ED, vid. supra). En el viejo modelo, como si de un tren se tratara, uno «se colocaba en los raíles» en una organización, sabiendo de antemano su recorrido, paradas y el día exacto de conclusión de su trayectoria (o jubilación). En dicho modelo, tenía sentido hablar de RR.HH. (como piezas sustituibles del sistema), pero desde los albores de la globalización (ya desde los años 70), ese paradigma entró en crisis, y hoy en día está llegando a su fin. Ello supone que:

a) las organizaciones buscaban la satisfacción de objetivos, funcionando como una maquinaria bien engranada, además de contar con piezas abundantes de recambio (RR.HH.);

b) ha predominado una visión mecanicista y burocrática de las relaciones laborales y las organizaciones empresariales, dándose paso a otro ciclo más organicista, incluso difuso, no solo por su incertidumbre, sino también por su desvanecimiento, al convivir lo tangible con lo virtual.

Para realizar un balance del devenir de las relaciones laborales y su modelo de RR.HH. (pasando por Administración de Personal y Capital Humano), no es necesario remontarse a sus antecedentes ${ }^{8}$, basta con evaluar el último siglo y medio, desde la $2^{\circ} \mathrm{rev}$. industrial, y el modelo fordista (de producción industrial en cadena), con su organización técnica del trabajo. Así, el primer velo a retirar en esta revisión, es el de la épica socialista: los avances logrados no son monopolio de partido o sindicato alguno, sino que se trata de una sinergia institucional convergente de reforma (en el periodo de entreguerras), que parte de la Oficina Internacional del Trabajo de la Sociedad de Naciones (más tarde, la Organización Internacional del Trabajo de la ONU), pasando por los parlamentos estatales en sus diversos niveles, hasta las directrices de implantación en el seno de las empresas, con la participación de comités de empresa y demás agentes intervinientes. Por tanto, todo arranca con

8 Posiblemente, las relaciones laborales basadas en el talento surgieron en la civilización occidental en los constructores de catedrales, al ser el único gremio itinerante y dependiente de su reputación, precursor de las Artes Liberales, v.g. medicina, abogacía, periodismo. 
la Segunda Revolución Industrial, aplicada al sector primario, cuando desaparecen buena parte de los tradicionales oficios agropecuarios y energéticos, además de impulsarse el sector secundario, con el desarrollo de las industrias con cadenas de producción, y con ellas, la aparición de las nuevas relaciones laborales. Así se produce una migración del campo a la ciudad, con un sinfín de cambios socio-culturales, no exentos de conflictos y urgencia de una ordenación al respecto.

De ahí que el auténtico despegue del Derecho del Trabajo (relativo al asalariado por cuenta ajena y en relación de dependencia), tiene su auge en el mencionado periodo de entreguerras, con el marco mínimo común dado por la OIT, desarrollado por parlamentos nacionales, y realizado en cada empresa. Dicho marco fue revisado y ampliado en el periodo de posguerra, con el boom del sector terciario y para dar el salto a EB y su diversidad: con trabajadores privados por cuenta ajena (Derecho del Trabajo) y propia (Derecho Mercantil), servicios de obra y de sociedad (Derecho Civil), empleados públicos (Derecho Administrativo), etc. En este periodo de entreguerras, H. Fayol (1930) y E. Mayo (1924) contribuyeron a la teoría de administración positiva, estudiando la eficiencia de los directivos en las organizaciones. Mayo (1924) estudió las relaciones laborales desde las teorías del economista V. Pareto y mostró que los sistemas de tiempos e incentivos no afectaban a la productividad (como ya se probara en la práctica en las fábricas de Ford). Le afectaban más los factores sociales, como la moral y las relaciones satisfactorias de un grupo de trabajo, es decir, los sentimientos, actitudes y complejidad motivacional (Sennett, 1998).

Hay que apuntar que ni la denominación ni la inspiración de la EB es originalmente socialdemócrata (más bien, muy criticada por la misma en un inicio, VV.AA. 1971). Su origen puede fijarse en socialistas fabianos universitarios, como Pigou (1920). Su nombre procede de la contraposición a la economía de guerra (en vez de war state, se pasó a welfare state), cuya realización fue impulsada finalmente por liberales, laboristas y democristianos (v.g. Lord Beverage, Lord Keynes, Adenauer, De Gasperi, Schuman). Tras en el periodo de entreguerras se pasa de RR.HH. focalizados en la contratación de trabajadores industriales por cuenta ajena, poco cualificados y no-diferenciados (de ahí la percepción como piezas intercambiables del sistema), a la cualificación de capital humano (término usado en la costa pacífica) y Administración de Personal (término usado en la costa atlántica). Ello hizo necesaria una atención específica a los puestos concretos y las personas más adecuadas para su desempeño. No obstante, pese a la transición cualitativa, se mantiene la visión mecanicista y burocrática, incluso aumentada: dado que, tras la devastación de la Segunda Guerra Mundial, solo el Sector público dispone de músculo para reactivar la economía, se procede a hibridar política y economía en el modelo de EB, 
nacionalizándose las empresas líderes de sectores estratégicos (v.g. Francia: France Telecom, Air France, Renault; España: Telefónica, Iberia, SEAT). En tal sentido, la Administración de Personal opera en los mismos términos que el resto de las Administraciones Públicas: convocatorias públicas de contratación vía sistemas de selección próximas al concurso-oposición, jerarquizándose y normalizándose empleados, etc.

En lo relativo a capital humano, conviene prestar atención a la retroalimentación positiva entre EE.UU. y Japón, aunque también termina alcanzando a otros tigres asiáticos: Corea del Sur, Singapur, Hong-Kong y Taiwán. A diferencia del modelo burocrático y direccionista europeo (en ocasiones con financiación estadounidense, v.g. ordoliberalismo alemán, degaullismo francés), las variantes asiáticas, pretenden ir más allá, dando lugar a la peculiar burocracia corporativa de conglomerados familiares favorecidos por el Estado (v.g. chaebols surcoreanos: LG, Lotte, Daewoo, Samsung, Hyundai). En dichas variantes, la burocracia no se debe tanto a los tasados procesos, pues se busca aligerarlos de manera resolutiva y expeditiva, sino a las jerarquías y vínculos psicosociales en los que se sustentan (se trata de una burocracia no de idoneidad, sino de identificación de misión-visión-valores). Se alude así a expresiones como:

- Toyotismo (también conocido como ohnoismo): si un ingeniero y consultor como Taylor formuló la organización científica del trabajo, aplicándose con éxito por un industrial como Ford de modo que sentaran las bases modernas de la producción en cadena y RR.HH. con selección y adiestramiento de mano de obra para grandes fábricas, en Japón fueron dos insignes ingenieros quienes hicieron realidad el toyotismo, yendo más allá (Gronning, 1997). De un lado, Kiichiro Toyoda (hijo del industrial textil, pero que hizo una reconversión de la compañía hacia el sector automovilístico); de otro lado, Taiichi Ohno, quien aprendiera de las prácticas del ejército estadounidense desplegado en su país (v.g. programas de adiestramiento TWI), combinándolas con planteamientos culturales propios, sobre todo taoísmo y budismo. De este modo, su puso en práctica el modelo kaizen de mejora, para la gestión de calidad y sin despilfarro. Se trata de una mejora continua, con reducción de: desperdicio (materiales sobrantes del proceso de producción), stock de almacén (tanto de materias primas como de producción), horarios y empleados (con rotación de turnos y equipos), etc. Así nació Toyota Production System (TPS). Tras la crisis energética e industrial de 1973, momento en que se desvanece la expectativa de desarrollismo y pleno empleo, los estadounidenses asimilan el modelo TPS, sustituyendo la producción en cadena por just in time o ajustada, bajo demanda y de reducción de costes. Se daba así lugar a otras propuestas de gestión, como la sustitución del sistema push (o previsión de ventas) por pull (o reposición, base del retail 
actual de supermercados), equipos de mejora, así como otros tantos orientados al no-desperdicio (v.g. production leveling, quick die changes, one-piece flow, flexible job assignments, removing non-value added work). Con dicho trasplante comenzará la desinstitucionalización empresarial y cierta precarización laboral.

- Kaizen Nissan (literalmente: cambio bueno en japonés): se trata de una versión actualizada de TPS, intensificando un modelo flexible y ágil de producción en conjunto. Estuvo impulsado por otra empresa japonesa de automóviles (Nissan), que destaca en los años 80 al expandirse internacionalmente y llegar a superar a la estadounidense GM —no solo por su gestión de RR.HH., sino por ser pionera en la producción de coches menos contaminantes- Su modelo se basa en la selección de trabajadores ágiles y colaboradores, incluso de manera trasversal, juntando taller y oficina, además de resolutivos y expeditivos. Una de sus reglas operativas es 2x2: tras la detección de un problema en la producción, se constituye un equipo interdisciplinario llamados círculos de calidad, inspirados por K. Ishikawa, que dispone de dos días para dar con la solución e implementarla en la cadena antes de dos horas (Feuer y Lee, 1988).

- Lean (es un préstamo del japonés, traducido al inglés, y suele entenderse como sistema ágil y ajustado): se alude a la producción innovadora desde los años 90, que no solo no se preocupa de no desperdiciar en la producción como se focalizaba TPS, sino que también integra la agilidad de respuesta de KaizenNissan, además de buscar la mejora de la experiencia del cliente, ofreciéndole más soluciones adecuadas: propuestas intuitivas, mayor comodidad, etc. La propuesta nace en las escuelas de negocio estadounidenses, con tesis doctorales como la de J. Krafcik en Sloan-MIT (1988), pasando luego a consultoras, tipo las de Womack (quien dejara de ser profesor de MIT para fundar Lean Enterprise Institute en 1997, y Lean Global Network en 2007). Con ello, se impulsa una cultura empresarial de mejora, añadiendo a todo lo anterior una vocación de heurística basada en retos y la proactividad de los colaboradores, lográndose una mayor motivación, además de perfeccionar y agilizar la cadena de valor (Womack et al 1990, 2003 y 2014).

Así comenzó la desinstitucionalización rígida del trabajo típica de EB, para pasar a otra flexible de ED, de trabajadores colaborativos y móviles. Tal transición no ha sido fácil ni agradable, más bien problemática:

a) por diferencias culturales: el Sudeste asiático comenzó su occidentalización en el s. XIX, intensificándose tras la Segunda Guerra Mundial, pero es un proceso inacabado y en muchos aspectos solo formal, por lo que los trasplantes pueden fallar. Sirva como muestra de la diferencia cultural —y su difícil traslado al resto 
de Occidente-- el caso de Japón, donde las huelgas no solo han sido de paros y piquetes, sino también de celo y sobreproducción: al producir más subvierte el sistema toyotista. Incluso, otra variante, es inundar el mercado del bien o servicio gratis: desde la sobreproducción automovilística y de derivados lácteos en los años 80 , hasta casos recientes en mayo de 2018, como la huelga de autobuseros de Okayama, que ofrecían transporte sin cobrar. Quizá las manifestaciones más llamativas, que prueba los problemas de trasplantes culturales, son los casos de karoshi, muerte por trabajo: 200 casos al año, aprox. (Frank, 2014); karojisatsu, suicidio por relaciones laborales: unos 2000 casos al año, (Amagasa et al, 2005); hikikomori, aislamiento social de jóvenes que realizaban teletrabajo: unos 500.000 casos (Rosenthal et al, 2012), etc.

b) por los responsables de su trasplante y sus velos de confusión y por el requerimiento de organizaciones maduras, comprometidas con el cambio. Con las guerras culturales (1960-80), en la universidad surge The New Left. Se alude a la $4^{\circ}$ internacional socialista o situacionismo, como los movimientos anti-sistema de protesta, como los hippies, que inspirara las revueltas universitarias de los años 60, sobre todo en EE.UU. (por influjo de Marcuse, Adorno, Bloch, etc.) y Francia (Sartre, Derrida, Foucault, etc.). Pero los planteamientos de estos autores fueron poco creíbles en términos económicos, hasta que se hibridaron con las visiones estatalizantes de Keynes, destacando autores tan populares como Galbraith desde Harvard ${ }^{9}$ así como la difusión de organizaciones como el Club de Roma desde 1968, con apoyo de investigadores de Harvard, MIT, etc. De este modo, se mezclaron reivindicaciones políticas de toma de conciencia y desburocratización con los planteamientos del Estado de bienestar y los problemas de calidad de vida, incluso los problemas de población, el crecimiento y sus externalidades, más su impacto en la naturaleza (Meadows et al, 1972). El caso es que, como pasara con los hippies, que se volvieron luego yuppies, la New Left y su New Economy hibridaron y necesitaron de su némesis: New Liberals. Al llegar al poder como generación, aumentaron los problemas sociales, etnoculturales, de género, etc. (Sánchez-Bayón, 2019f), así como el nivel de endeudamiento que consumió la riqueza de siguientes generaciones, amén de la mayor devastación del medioambiente, postulando un neomaltusianismo eugenésico frente al cambio climático (Andreu et al, 2019; Sánchez-Bayón, 2019a). Desde los años 80 , cuando se generalizara el trasplante cultural de los modelos planteados al resto de Occidente, por urgencia de reconversión y no por convencimiento pleno, resulta que los encargados de dicha labor fueron los baby-boomers y la

Schumpeter (y su discípulo Samuelson) ya lo venía haciendo, pero no llegaba igual a los universitarios (Lindbeck, 1971). 
generación x, ya yuppies de dirección. Ello extendió un cúmulo de velos sobre la desinstitucionalización flexible, que se volvió así precaria para las siguientes generaciones (la generación y, más los milenios, conocidos como los mileuristas).

La flexibilidad, como una condición física, se define como aquello que permite a los materiales la deformación ante presiones (como las crisis) sin llegar a partirse y para recuperarse luego. Pero crisis tras crisis y dada la desinstitucionalización promovida, las nuevas generaciones, pese a su mayor cualificación, disfrutan de menos derechos, teniendo que saber negociar sus beneficios laborales en cada nueva experiencia profesional (más allá del salario emocional). Al riesgo de rechazo de trasplante cultural y su inadecuada operación, como se ha indicado, hay que añadir el requerimiento de organizaciones maduras: aquellas focalizadas, ya no en la mera producción y los beneficios, sino en las personas y la sostenibilidad, basándose en un modelo de felicidad y bienestar. Sirva como adelanto el siguiente apunte: hasta la globalización, tanto la Psicología como la Psiquiatría abordaban la mente humana desde la negatividad (v.g. el diagnóstico de trastornos como los recogidos en DSM y CIE), por lo que un no tan típico psicólogo judío neoyorkino, Martin Seligman, comenzó un giro hermenéutico hacia la autoayuda y, finalmente, la aplicación de un auténtico enfoque positivo: cómo ser feliz (incluso en organizaciones sociales, como son las empresas). Como Profesor de Psicología de Cornell y Univ. Pennsylvania (posterior director del Dpto. Psicología), usó sus contactos y publicaciones (Seligman, 2002 y 2011), para llegar a ser Presidente de la American Psychological Association-APA en 1998; desde dicha plataforma comenzó a postular con éxito el cambio de paradigma, desde la educación al trabajo.

Por tanto, los cambios en los planteamientos de RR.HH. (ante su declive, Sánchez-Bayón 2019d y e), pasando de la rigidez jerárquica y largoplacista a la flexibilidad trasversal y cortoplacista, son previos al agotamiento de la EB, con su burocracia y direccionismo, solo que agravándose todo ello con las crisis - ya citadas - de la globalización. Resulta así urgente y necesario un nuevo paradigma para la posglobalización. Para conocer el actual estado de la cuestión, se ofrece a continuación un breve diagnóstico y pronóstico de las relaciones laborales en el marco de la fase gig de ED, introduciéndose novedosas nociones relacionadas con los colaboradores (v.g. knowmads, flexecurity, part-time jobs mix), y las organizaciones (v.g. wellness \& happiness model).

Como se viene señalando, la fase gig de ED, aglutina manifestaciones como ECC, EA y $\mathrm{EN}^{10}$. Su nombre procede de una expresión estadounidense, relativa a

10 Se recuerdan aquí algunas notas mínimas sobre la economía digital (ED), máxime en su fase gig actual, que comprende: a) ECC, se basa en redes sociales, reciclando bienes y servicios compartidos (v.g. AirBnB, Uber); b) $\mathrm{EA}$, se basa en big-data, internet de las cosas-IoT, inteligencia artificial-IA, realidad aumentada, virtual y mixta-RA-RV-RM, 
las giras o bolos artísticos: un profesional ofrece sus servicios para una actuación y, si gusta, repite. Algo parecido funciona la economía gig: un profesional debe estar en redes sociales y plataformas, pendiente de la llamada para su actuación, que es valorada y de ello depende si continúa prestando ese servicio en su zona, incluso en otras plazas. Luego, ¿cuáles son los pros y contras de la fase económica gig?

a) A favor: permite que gente corriente de todo el mundo pueda iniciar negocios y participar en mercados sin intermediarios y respetando el medioambiente al compartir, reciclar y alquilar, frenándose la obsolescencia programada y destino basura electrónica que al desecharse lastiman el medioambiente. Uno es su propio jefe, gestionando su tiempo e ingresos; en principio, cada cuál conoce su talento - al menos, sus capacidades-, poniéndose al servicio de los demás; no hay tanta burocracia y direccionismo, sino más bien, el riesgo se convierte en una oportunidad y experiencia, que además se comparte con los otros, generando una inteligencia colaborativa, añadiendo aún más valor a la labor realizada (siendo también un primer hito del camino a la SC).

b) En contra: al virtualizarse, es decir, operar vía internet, desaparecen las oficinas y la camaradería, dificultando la sindicación y defensa de derechos laborales. Dado que no se pagan apenas impuestos ni cotizaciones, no hay casi protección laboral, desapareciendo las vacaciones pagadas, los subsidios de desempleo o enfermedad, las jubilaciones, etc.

Al no haber tanto control de los mercados ni de los trabajos, resulta muy difícil su fiscalización por los poderes públicos. Esto ha hecho saltar las alarmas, acometiéndose restricciones: se intenta regular en contra de las nuevas iniciativas, como los apartamentos turísticos (v.g. AirBnB, Rentalia), vehículos de transporte con conductor (v.g. Uber, BlaBlaCar), bazares de segunda mano (v.g. Wallapop, eBay, OpenBazaar), etc. Tal freno, ya no es porque escapen a su gravamen, sino por la falta de influencia en su devenir (no pudiendo establecerse restricciones, v.g. licencias, colegiaciones), lo que lleva a vulnerar el monopolio estatal del sistema social (Schor, 2016). Los ciudadanos ya no necesitan de los poderes públicos y sus fedatarios para la prestación y validación de bienes y servicios, sino que pasan a ser las propias comunidades de particulares quienes lo hacen, con recursos como las puntuaciones, comentarios y rankings; así como la tecnología blockchain, operativa a raíz de la crisis de valores de 2008. Cierto es que la tendencia de las redes

etc., articulándose mediante 5G, block-chain, smart-contracts y DAOs (v.g. fondos de inversión en flota de coches autónomos, fintech); c) EN, se basa en el talento y la creatividad aplicándose a la experiencia y el entretenimiento (v.g. gastronomía, turismo, videojuegos, festivales). Con la crisis COVID-19, se ha dado una reacción, de vuelta a la industrialización, cuando en realidad lo que se requiere es de una auténtica digitalización y transformación laboral (v.g. el teletrabajo no puede tipificarse por horas, sino por objetivos resueltos). 
sociales, plataformas y aplicaciones en las que se basa la economía gig, ha sido la de concentración, como ya pasara con las principales multinacionales en la EB, pero la gran diferencia es el influjo de la destrucción creativa con grandes cambios en poco tiempo, una constante heurística y la renovación tecnológica, etc., por lo que periódicamente se van renovando los líderes de sector, así como los propios sectores. Sirva de ejemplo la industria musical — por continuar con la alusión a los bolos-, que se redujo a cuatro grandes conglomerados, dando lugar a relaciones de elefantes y hormigas (o sea grandes compañías y cada uno de los profesionales), pero que se ve sometida a una destrucción creativa constante gracias a la tecnología.

La fase gig acaba con buena parte de la burocracia y el direccionismo, devolviendo cierta autonomía al colaborador — quien ya no es trabajador dependiente o mano de obra-; eso sí, incrementa el riesgo y la incertidumbre, además de exigirse agilidad, adaptabilidad y talento (tanto en el valor diferencial propio, como en el aportado a la relación laboral). En lo tocante a RR.HH., la economía gig está afectando sobre todo a dos tipos de profesionales, en polos opuestos: knowmads (muy cualificados) y freeriders (poco cualificados).

a) Knowmads (juego de palabras del inglés: know+nomads=nómadas del conocimiento, tipo médicos, abogados, profesores, ingenieros, diseñadores, etc.): son profesionales del conocimiento, altamente cualificados, y abiertos a la movilidad. Sirva de ejemplo el caso de los colaboradores en las holocracy startups o empresas hocráticas (autogestionadas o sin-jefe) — ¿cómo contratar a los mejores y luego decirles lo que tienen que hacer, ralentizando todo con barreras de supervisión? - desde pioneras como Zappos (empresa de zapatos) o Gore (ropa gore-tex), pasando por DaVita (servicios de salud), hasta Valve (videojuegos), Netflix (entretenimiento audiovisual), Rastreator (buscadores y comparadores de servicios) o Ternary Software (servicios informáticos), y ni que decir en sectores renovados por la destrucción creativa, tipo FinTech. En estas compañías todos pueden proponer y asumir proyectos, sin puestos ni roles fijos, sino a modo de redarquías - más allá de las tradicionales cooperativas-. Así, se cobra según participación y resultados, además de darse manifestaciones como: el teletrabajo desde cualquier lugar, siendo el móvil la oficina; flexecurity al ser colaboradores cualificados, conocen sus derechos y pueden permitirse renunciar a la relación laboral —esa es su seguridad—, por lo que las condiciones están abiertas a negociación; part-time job mix, al colaborar en startups para asegurar facturación —no ya salario-, debe tenerse una cesta de colaboraciones. Incluso, se recomienda la inversión de la percepción, empezando a considerar a los empleadores como clientes, de modo que desaparece el estigma psicosocial del despido, y solo se trata de buscar otra vía nueva de financiación (Moravec, 2013). 
b) Freeriders: son los jinetes solitarios, quienes participan sin tanto control administrativo. En RRHH se alude a operadores poco cualificados, obligados a la movilidad (v.g. repartidores, reponedores, vigilantes). Uno de los casos más ilustrativos es el de los repartidores de Deliveroo o Glovo. En sendas compañías, existe un sistema abierto y ágil de contratación, pero lleno de riesgos y costes ocultos: personas en situación irregular pueden empezar a trabajar de inmediato ${ }^{11}$. Eso sí, casi sin coberturas y teniendo que registrarse varios repartidores bajo una misma cuenta, de modo que aseguren el cumplimiento de las entregas y su frecuencia, para permanecer visibles en los rankings de reparto de servicios. Como corrección a esos elefantes, van surgiendo alternativas como La Pájara, u hormigas de reparto especializado (v.g. para consultoras, despachos, firmas).

Como resultado del balance realizado, se constata la caducidad y cambio paradigmático económico, empresarial, laboral y RR.HH., etc., en el sector terciario (en transición al cuaternario), con constantes correcciones a mejorar durante la vigente posglobalización. Por ello, tanto el diagnóstico como el pronóstico resultan menos claros de lo deseable, al tener que convivir aún el rígido modelo de EB y el flexible $\mathrm{ED}$, dando lugar a intermedias zonas grises de precariedad. Lo que sí es claro es que cada vez se reduce más la importancia de la EB, con sus relaciones laborales burocratizadas y dirigidas a asalariados dependientes, expuestos a una mayor precariedad por no asumir el riesgo de descubrir su talento, cultivarlo y ofrecerlo a los demás. Además, la precariedad de la que se viene hablando, con seguridad, no es imputable a la Cuarta Revolución Industrial y su transformación digital, que destruye tantos trabajos, como nuevos crea; como ya pasara en las otras revoluciones industriales, sino a la mala práctica de baby-boomers y gen $x$ en diversos niveles:

a) económico: pese a ser los más beneficiados de EB, la han llevado a su colapso al haber consumido más riqueza de la generada, gastando la de las siguientes generaciones, vía endeudamiento;

b) empresarial: han promovido la desinstitucionalización de las compañías, desde la deslocalización y el dumping de mano de obra — corregida con la transformación digital-, hasta la intensificación de figuras laborales precarias, tipo becario - en vez del contrato en prácticas y de aprendizaje-, por lo que ya no hay un proyecto común ni sostenibilidad, sino que cada cual tiene su propia agenda oculta, saltando de proyecto en proyecto (Pérez-Huertas et al, 2013);

11 Cualquiera que disponga de un bien o servicio del que no requiera en ese momento (v.g. una habitación, un coche, minutos de teléfono), puede ponerlo a disposición de los demás, ganando todos, menos el Estado, dado que tiene más difícil su fiscalización. Incluso, pueden participar inmigrantes irregulares, solo que lamentablemente, ven reducida su disponibilidad — temporalmente - a la condición de freeriders, ya que la de knowmads requiere del sorteo de trabas administrativas (Navajas et al, 2016). 
c) RR.HH.: al mismo tiempo que ha habido hiperregulación, se ha intensificado el fraude de ley, de modo que a los nuevos trabajadores se les ha contratado por debajo de su cualificación, imponiéndoseles unas condiciones abusivas y salarios inferiores, bajo una falsa promesa de futura mejora y de que otros vendrán a asumir la sobrecarga. Debido a la desinstitucionalización, ya no hay carreras laborales al uso, ocupándose un puesto multitarea mientras convenga, pues a la dirección ya no se llega por promoción interna, sino vía caza-talentos. En definitiva, es el fin de EB y sus RR.HH. La economía gig solo es una fase más, con errores que corregir si se desea alcanzar la sociedad del conocimiento; por lo que es recomendable cuanto antes aprender cuáles son los nuevos paradigmas y cómo operar al respecto.

A continuación, se va a tratar la cuestión desde las medidas político-económicas tradicionales, como el proteccionismo vía SMI y sus implicaciones reales (en realidad, no protegen al asalariado menos capacitado y con peor remuneración, sino que, a largo plazo, se provoca su expulsión del mercado). Dicho planteamiento, si se extiende a los nuevos colaboradores (en especial a los freeriders), puede provocarse el mismo efecto.

\section{EVALUACIÓN DE MEDIDAS ADOPTADAS CON LA CRISIS COVID-19: ESTUDIO DE CASO DE SMI Y SUS IMPLICACIONES ECONÓMICO-LABORALES}

Durante la década de 1880 , con la $2^{\circ}$ rev. industrial, tiene lugar la desaparición de la mitad de los trabajos en el sector primario (por su mecanización), con grandes migraciones a las ciudades, dándose paso a nuevas profesiones en el boom del sector secundario y el despegue del sector terciario. También por entonces, fallece Marx (no así el marxismo, tan recurrente en las universidades, medios de comunicación y think-tanks, Sánchez-Bayón, 2019f), y comienza una nueva etapa socialista: el revisionismo o socialdemocracia (Bernstein, 1899, 1901a y b). Según la $2^{\circ}$ internacional, ya no es necesaria la revolución del proletariado, sino el ascenso político dentro del sistema democrático de partidos y sindicatos de clase, que logren políticas públicas tuitivas para los trabajadores y su bienestar. También, en dicho periodo se refunda el Ku Klux Klan (KKK), ganando elecciones locales, con una medida estrella: el salario mínimo interprofesional (SMI), para evitar que los afroamericanos recién emancipados pudieran acceder a trabajos, en competencia desleal (al aceptar bajos sueldos), provocándose a la postre su gran migración a las ciudades del Norte y Medio Oeste. Dado el pensamiento débil (Sánchez-Bayón, 2017a; Valero et al, 2018), surgido durante las guerras culturales (1960-80) y generalizado tras la globalización, resulta urgente y necesario el aclarar ciertas falacias generalmente aceptadas sobre SMI: no mejora las condiciones laborales, sino que las empeora, pues su beneficiario final es para 
su impulsor (los poderes estatales), hoy llamados Sector Público ${ }^{12}$. La experiencia de la socialdemocracia escandinava (durante las citadas guerras culturales, y que pronto tuvieron que cambiar, para volver a crecer) ${ }^{13}$, probó que el SMI no beneficiaba al trabajador, sino al Estado de bienestar, al pretender una mayor financiación vía retenciones salariales — que no fue tal, y además causó una pérdida de poder adquisitivo al trabajador y, a la postre, un gran endeudamiento nacional, vid. supraPor ello, hoy dicha los países nórdicos no gravan tanto la generación de renta, como sí lo hacen al consumo (de modo que se estimule una cultura del ahorro, en vez del endeudamiento, como sí parecen seguir buena parte de los países mediterráneos, donde la economía de bienestar estatal está más anclada en su direccionismo y clientelismo).

Sirva la mención telegráfica (no exhaustiva, solo ilustrativa) de algunas negatividades del SMI (Sánchez-Bayón, 2019g): en un mercado laboral libre (como se supone postula el art. 35 de la Constitución española de 1978), el salario se establece en el cruce de la oferta y demanda (como precio de equilibrio); sin embargo, en un mercado regulado y con SMI, la oferta se contrae (hay menos contratación, al ser más cara y decrecer la utilidad marginal). De tal manera, la mano de obra no cualificada se vuelve un lastre (por suponer un coste fijo muy alto, en relación a su baja productividad), de ahí su sustitución por robótica y programación (como ya viene pasando en vigilantes de parkings, cajeros de supermercados y grandes superficies, camareros de franquicias de restauración, etc.). Con SMI se levanta una barrera legal de acceso a nuevos trabajadores (jóvenes, inmigrantes, etc.), incluso para aquellos en proceso de reconversión (mayores, parados de larga duración, etc.), debido a los altos costes fijos de Seguridad Social, IRPF, et al. Más aun, con SMI se reduce el poder adquisitivo de todos: el trabajador no cualificado vive un espejismo, al creer que gana más, cuando en realidad pierde las ayudas por bajos ingresos (v.g. becas escolares, ayudas al transporte), las exenciones fiscales (v.g. no tributación de IRPF), y para colmo su

12 Los poderes estatales en el s. XIX pasaron de la matriz mínima de poderes horizontales (Ejecutivo, Legislativo y Judicial), a descentralizados (tanto territorial como competencialmente), ampliándose sus administraciones de apoyo, hablándose así de Administraciones Públicas. A inicios del s. XX, de manera complementaria, surgieron novedosos poderes estatales trasversales de vocación garantista (v.g. Tribunal Constitucional, Defensor del Pueblo). A mediados de siglo, hubo un cambio de terminología, para restar violencia y procurar una legitimidad de conocimiento (de potestas a auctoritas), por lo que empezó a hablarse de Instituciones Públicas y a sus representantes como Autoridades Públicas. Finalmente, con el éxito de EB, se ha terminado instaurando el concepto difuso del Sector Público: agencias estatales (v.g. meteorología), institutos (v.g. estadística), confederaciones (v.g. hidrográficas), corporaciones (v.g. colegios profesionales), sociedades (v.g. consorcios energéticos y de transportes), etc. Sánchez-Bayón, 2016b y 2017 b.

13 Así queda probado en las estadísticas de la OCDE y en índices internacionales, como Doing Business (DB) del Banco Mundial: los países nórdicos (Noruega, Suecia, Finlandia y Dinamarca) se hallan entre los diez principales de dicho índice (y de otros como IDH-ONU, percepción de la corrupción de la Fundación Transparencia, etc.); mutatis mutandis, cabe predicarse igualmente para los anglosajones, en especial (dentro de la Commonwealth of Nations) los casos de UK, Canadá, Australia y Nueva Zelanda. 
dinero vale menos (por el efecto inflacionario, vid. supra). También se perjudica al trabajo cualificado, al ver recortada la parte variable de su salario (v.g. bonus), que es de donde se detrae para compensar la subida de SMI. Incluso, a medio plazo, el Sector Público (impulsor de la subida de SMI), termina comprobando que no se alcanza la cuota de recaudación prevista (al disminuir la contratación y aumentar los despidos), de modo que para mantener tal gasto público no productivo asumido, se recurre a un aumento del déficit (que desajusta el presupuesto, para poder terminar el año fiscal) y un mayor endeudamiento (para abonar las prestaciones y subsidios por desempleo, las prejubilaciones, las ayudas sociales, etc.). El empobrecimiento y dependencia al que conduce el aumento de SMI, dado su efecto inflacionario, no solo se observa en los trabajadores por cuenta ajena, sino que también se transfiere (por otra falacia, como es la igualitarista) a los trabajadores autónomos ${ }^{14}$ —eso sí, no igualados en derechos - y pensionistas - dicho sea de paso, su sistema urge de un tránsito inmediato generalizado de reparto a capitalización-. Resulta que, lo que se presentaba como una mejora, en realidad constituye una precarización expansiva, ya que el SMI se vuelve el salario medio interprofesional: el mileurismo — denominación acuñada en España para quienes tiene un salario mensual de 1000 euros (normalmente jóvenes y aquellos con poca cualificación) —, se manifiesta como la realidad dominante (amén de la economía sumergida), solo que valiendo menos. Téngase en cuenta que, dada la subida impuesta de SMI (sin sustento en la mejora de la productividad), la misma se repercute a los precios de los bienes y servicios, además de aumentarse así la presión fiscal (sobre la burbuja generada); al resultar insostenible un escenario así, por recortes laborales y caída de la recaudación, se incurre entonces en un mayor déficit y deuda para intentar cubrirlo, de tal suerte, al final se repercute todo ello a las siguientes generaciones, que no solo serán las pagadoras, sino que se habrá consumido parte de la riqueza que les correspondía (de ahí la paradoja de la mayor cualificación con un menor nivel de vida). Baste recordar coyunturas pretéritas, como la española, de huelgas generales y disturbios sociales, que finalmente pudieron resolverse vía los Pactos de la Moncloa de hace cuarenta años (la subida indiscriminada de salarios disparó la inflación a un 27 \%: de ganar miles de pesetas se pasó a cientos de miles, ocurrió igual en el resto de precios, por lo que el poder adquisitivo se desplomó, siendo necesaria una regulación rígida, para

14 En una interpretación perversa del sistema -y sin suficiente respaldo legislativo (en todo caso, vía instrumentos asimilados, como los decretos-leyes, con déficits de legitimidad y validez)-, se obliga a los autónomos a aportar unas cotizaciones más elevadas, con mayores retenciones fiscales, como si hubiera un incremento de su salario; en realidad, se están inflando sus costes, reduciéndose su escaso margen de beneficio -y eso dando por sentada la ficción de que siempre ha de ganarse, cuando lo habitual es tener algún trimestre negativo, a compensar luego-. Otro error interesado es identificar al autónomo con el profesional liberal no colegiado, junto con el industrial y el comercial, pese a que en realidad dicha categoría comprende a otros muchos colectivos, más vulnerables aún, como son los agricultores, ganaderos, trabajadores de servicio doméstico y de cuidados, etc. 
evitar descontroles pasados, pero ello redujo la productividad, además de fijar un techo de cristal a la riqueza).

\section{DISCUSIÓN Y CONCLUSIONES: GANADORES Y PERDEDORES}

Los cambios citados al inicio de este texto se manifiestan cada vez más en la realidad: la crisis de valores de 2008, seguida ahora de la crisis de la COVID-19 y el gran confinamiento, ponen de manifiesto la urgencia de revisar y reformular los paradigmas, pues cada vez se dan más problemas fuera de los mismos, resultando mínimos aquellos que se logran reconocer y gestionar, aunque de manera deficiente. Sirva como ejemplo concreto las fallidas políticas económico-sociales (sanitarias, laborales, etc.) de EB de buena parte de los países de la Unión Europea (sobre todo, del bloque mediterráneo), frente a los modelos chaebol o keiretsu (las corporaciones familiares) orientados a la ED de los tigres asiáticos (v.g. Singapur, Corea del Sur, Taiwán). Incluso éstos requieren de revisión, pues responden a modelos alternativos de los años 60 del siglo pasado (v.g. Corea del Sur, dado el agotamiento de modelo, se está planteando una adopción de EB, cuestión fallida de partida, como se viene aclarando, además de requerir el subarriendo de mano de obra en Corea del Norte y el cese de la guerra cultural-comercial con Japón).

En lo tocante a los cambios en las relaciones laborales y la organización empresarial, se ha buscado ofrecer aquí una síntesis crítica de su desarrollo en el marco rígido, burocrático y dirigido de $\mathrm{EB}$, prestando especial atención a su modelo de RR.HH., dada la emergencia del paradigma del talento y el estímulo de la gestión de la felicidad para la posglobalización. A lo largo del texto, se han ido sembrando ideas clave, tipo: el agotamiento de RR.HH. por cumplimiento de objetivos y ciclo; el balance de los cambios por la transición de EB a ED, aterrizándose en su impacto en RR.HH. (con el paso de un modelo direccionista y burocrático de asalariados titulados replicados, otro modelo de felicidad de colaboradores talentosos y motivados); el diagnóstico y pronóstico laboral ante la economía gig, con dos perfiles afectados y polarizados (knowmads $\&$ freeriders), etc. También afecta en todos estos cambios la propia destrucción creativa, así como a la emergencia del talento: cualquier organización madura requiere de colaboradores talentosos, empezando por quienes deben gestionar dicho talento. Hoy en día, un responsable de gestión cultural y desarrollo de talento es clave, pues como un entrenador, conoce a su equipo, ayudando en el crecimiento personal y profesional de todos y cada uno, para «salir a ganar». En cuanto a la parte cultural, no solo vela por el buen clima laboral, sino que ha de promocionar una cultura organizacional participativa e integradora (v.g. redefiniendo y haciendo accesible la misión, visión y valores de la compañía, el reglamento interno de la empresa, la resolución de conflictos y su prevención). Luego, un gestor cultural 
y desarrollador de talento ha de ser empático y pragmático a la par, debe seguir la regla 80/20: la mayor parte del tiempo apoyando a los colaboradores, y la menor posible dedicada a papeleo.

Tras abordarse la caducidad del modelo de RR.HH. y la emergencia del talento (para su adecuación a H2030 y SC), se espera que tal alusión sirva para invitar así a un debate de mejora (incluso, más allá de la coyuntural crisis de la COVID-19, pues la misma, solo ha sido un acelerador de los cambios en curso). Resulta que, en perspectiva, las crisis son cada vez mayores: la de 1998, fue una crisis por derivados, solucionada por el rescate de Wall-Street; la de 2008, fue una crisis por deuda, solucionada por el rescate de la Reserva Federal-FED; la actual, es una crisis por deuda y falta de liquidez, que posiblemente sea solucionada por el rescate del Fondo Monetario Internacional-FMI (Rickards, 2016 y 2020). Más aún, se trata de una crisis múltiple (sanitaria, financiera, laboral, de vivienda, etc.), en escenario cuántico: tanto inflacionario como deflacionario, por lo que cualquier intento corrector por parte del Sector Público, puede provocar un efecto pendular, agravando el problema.

Con la crisis de la COVID-19 ya se ha digitalizado por completo el consumidor, quedando por hacerlo los trabajadores y las empresas. El modelo de relaciones laborales es distinto al caduco de EB: ya no se es un técnico, acreditado por un título académico, que está vinculado a una replicante cadena de producción. Con ED, solo serán trabajadores (asalariados por cuenta ajena), los pocos que desconozcan su talento, por lo que no pueden reconvertirse en colaboradores. Los auténticos colaboradores son los knowmads (quienes se transformarán a la postre), pues lo freeriders están llamados a desaparecer también, por lo que no conviene adoptar políticas económicas proteccionistas en dicho sentido, tales como el SMI. Algo así solo retrasa la transformación de los knowmads y la extinción de los freeriders, volviéndose agónico y traumático el proceso.

En definitiva, una medida proteccionista (ergo desglobalizadora), como es el SMI, resulta una herramienta económica peligrosa (especialmente en manos populistas y con discursos de pensamiento débil), pues genera falsas expectativas de crecimiento (por aumento de masa monetaria y estímulo del consumo), que en realidad se realiza en un aumento de la inflación y de la fiscalización, así como un malbaratamiento del dinero (como denunciara ya el Padre Molina de la Escuela de Salamanca, calificando el bastardeo de la moneda como el impuesto a los pobres). A continuación, a modo de recapitulación, permítase esbozar una síntesis mínima del efecto domino, que tiene el empleo de la subida indiscriminada del SMI, al darse lugar a un deterioro político-jurídico y económico-social en cascada: una de las primeras consecuencias es el aumento de la inflación (por subida generalizada de precios, con pérdida de 
poder adquisitivo), provocándose un desajuste del IPC (confirmándose dicha pérdida de poder adquisitivo); también se produce una mayor presión fiscal, cuya recaudación cae a medio plazo, por el efecto Laffer (al aumentarse los costes laborales, se reduce su oferta, por lo que hay menos posibilidad de gravar, por mucho que se suban los impuestos — moviéndose la economía de lo formal a lo informal—); otro efecto es el del levantamiento de barreras artificiales para los actores económicos, en especial, para quien venía a beneficiar (trabajadores poco cualificados y sin aportación de valor), pues el aumento de los costes fijos de factores no productivos sirve de incentivo para su sustitución vía digitalización (por lo que tras la fantasía de la subida salarial, su poder adquisitivo se pierde con la retirada de ayudas y el aumento de la presión fiscal, hasta que finalmente llegan los despidos, ya que es más barato y sostenible su sustitución por robotización y programas); ante la distorsión de mercados ocasionada, el Sector público pretende compensar los reajustes (conforme a su supuesta labor redistributiva), pero para ello ha de incumplir con el presupuesto y aumentar el déficit, de modo que se rompa el techo de gasto, fomentándose el mismo (eso sí, no el productivo, como son las inversiones y el fomento, sino las ayudas, acrecentando la dependencia y las redes clientelares), lo que en realidad lastra aún más la economía (acentuando y prolongando la tendencia del ciclo bajista, además de consumir la riqueza de las siguientes generaciones); con todo ello, al final, no solo se ha causado una pérdida generalizada de poder adquisitivo y un mayor endeudamiento de la sociedad (extendiéndose de forma intergeneracional), sino que además se ha vuelto el trabajo una suerte de bien altamente gravado y escaso (dado el desempleo, prejubilaciones, informalidad o economía sumergida, etc., siendo sustituido por robótica y programación). Así que el SMI, aumentado de manera indiscriminada, a corto plazo (en un par de trimestres, según lo abierta que sea la economía) puede parecer que beneficia al trabajador, pero a medio plazo (pasado un año) solo habrá ganado el Sector Público (al recaudar un poquito más y disponer de las ayudas que ya no han entregado en el corto plazo previo), para terminar disparándose precios, destrucción de empleo y aumento exponencial del gasto, para compensar los efectos de la burbuja provocada (v.g. Rep. Weimar en años 30, Rep. Cuba desde años 60, Rep. Camboya en años 70, Rep. Argentina en 1989-90 y desde 2001, Rep. Venezuela desde 1999). Ni aun siendo un gran experto macroeconómico se llega a dominar el uso correcto del SMI como herramienta cortoplacista, para enfriar o calentar la economía, influyéndose en el consumo —rara vez sale bien la jugada de alquimista y, en cambio, sí se causa confusión de confusiones-. Lo que es seguro, es que el SMI, se sigue presentando — de manera anacrónicacomo uno de los logros de EB, cuando en realidad está llamado a ser uno de sus sepultureros (por el populismo económico que pondrá fin a la ya de por sí caduca EB). Por fortuna, en ED (al menos, en su fase gig actual, con ECC, EA y EN), no tiene 
cabida el SMI, pues la facturación dependerá del talento de cada cual (y no de título alguno o antigüedad acumulada). Mientras se produce la transición de EB a ED (en el plazo mundial, como es H2030), ¿tiene sentido un SMI generalizado y uniformizante? El SMI, los convenios sectoriales, etc., resultan herramientas de EB de los años 60, en la que se tendía a la uniformidad y se expulsaba del sistema todo aquello que resultara diferente y disruptivo (pasando hoy lo contrario, v.g. modelo GAFA). En economías más competitivas (y adaptativas), como la estadounidense, poco a poco va despareciendo el abanico de SMIs (según sector y territorio), resultando algo orientativo y residual. Así pasa también en los países nórdicos y helvéticos (Suiza, Italia y Austria), donde no existe el SMI, sino salarios más altos según productividad.

En definitiva, el SMI puede considerarse una idea cargada de buenas intenciones, aunque ha resultado a la postre una mala práctica, pues su incremento generalizado, sin base real y solo regulatoria, únicamente ha supuesto un desestabilizador económico de efectos multiplicadores nocivos, con un buen número de trabas a la actividad económica y repleto de costes ocultos (en su mayoría, externalidades negativas): al final, no solo pierden los asalariados poco cualificados (a quienes se pretendía beneficiar), sino que todos pierden (algo lógico, sobre todo para los defensores de EB - y detractores de ED-, que entienden la economía como un juego de suma cero, por lo que se crea una burbuja para luego reventarla y socializar los costes). El problema añadido es que impide también el avance de las nuevas relaciones laborales con la transición digital, reduciéndose con mucho el factor productivo correspondiente (al destruirse las nuevas oportunidades laborales).

En este texto solo se ha planteado la punta del iceberg, pues entre las medidas de EB siguientes a implementar, dada la rigidez introducida por el SMI en el mercado de trabajo, se prevé la compensación vía el recurso del ingreso o renta vital, la contratación pública, etc.; pero todo ello, ya será objeto de estudio de otras publicaciones.

\section{REFERENCIAS}

Amagasa, T., et al. (2005). Karojisatsu in japan. Journal of Occupational Health, 47(2), 157.

Andreu, A., et al (2019). Claves de Administración y Dirección de Empresas en la Posglobalización. Delta Publicaciones.

Bernstein, E. (1899). Die Voraussetzungen des Sozialismus und die Aufgaben der Sozialdemokratie. Dietz.

Bernstein, E. (1901a). Zur Geschichte und Theorie des Socialismus gesammelte A6handlungen. Akademischer Verlag für soziale Wissenschaften.

Bernstein, E. (1901b). Zur Theorie des Lohngesetzes und Verwandtes. Probleme des Socialismus. Dümmler. 
Caravaggio, L. (2016). Economía y felicidad. Estudios Económicos, 67, 97-118.

De la Vega, J. (1688). Confusión de confusiones (Taller de Castro: Ámsterdam, 1688; reed. y trad., vid. Madrid, Soc. Estudios y Publicaciones, 1958).

Deloitte (2020). Lasting lockdown habits: a new digital consumer? Digital Consumer Trends 2020 (URL: https://www2.deloitte.com/uk/en/ pages/technology-media-and-telecommunications/articles/ digital-consumer-trends-lockdown-behaviour.html; consultado: sept. 2020).

Díaz-Fonseca, M., et al (2012). Las empresas sociales en España, GEZKI, 8, 143-64.

Dupont, L. (2019). Agile innovation. Journal of Innovation Economics y Management, 28, 1-5.

Fayol, H. (1930). Industrial and General Administration. Pitman.

Feuer, D. y Lee, C. (1988). The kaizen connection. Training, 25(5), 23.

Frank, R. (2014). Karoshi. Sherwood Park News, 24, 24.

Gronning, T. (1997). The emergence and institutionalization of toyotism. Economic and Industrial Democracy, 18(3), 423-55.

Keynes, J. M. (1936). The General Theory of Employment, Interest and Money. Macmillan.

Lindbeck, A. (1971). The Political Economy of the New Left. Harper.

Manzanero, D., et al (2014). Philosophical challenges of plurality in a global World. Cambridge Scholars Pub. Mayo, E. (1924). Revery and industrial fatigue. Journal of Personnel Research, 3, 273-81.

Meadows, D. et al (1972). The limits to growth. Universe Books.

Moravec, J. W. (2013). Knowmad society. On the horizon, 21(2), 79-83.

Navajas, V., et al. (2016). Inmigración y emprendimiento en la globalización. Delta.

Pigou, A. (1920). The Economics of Welfare. Macmillan.

Pérez-Huertas, J., et al (2013). Nuevas aportaciones en Teoría económica y empresarial. Torre de los Lujanes, 69, 127-51.

Ricardo, D. (1817). On the Principles of Political Economy and Taxation. John Murray.

Rickards, J. (2016). The rod to ruin. Penguin.

Rickards, J. (2020). The New Great Depression. Portfolio.

Rifkin, J. (2000). The Age of Access. Putman.

Rojas, M. (2014). El estudio científico de la felicidad. FCE.

Rosenthal, B., et al (2012). Hikikomori. International Journal of Mental Health, 41(4), 82-95.

Sánchez-Bayón, A. (2016a). Problemas y retos para alcanzar la sociedad del conocimiento. Delta.

Sánchez-Bayón, A. (2016b). Derecho Público General. Delta.

Sánchez-Bayón, A. (2017a). Revelaciones conceptuales y lingüísticas de la posglobalización. Carthaginensia, 33(64), 411-58. 
Sánchez-Bayón, A. (2017b). Lecturas fundamentales de Derecho Político y Constitucional. Sindéresis.

Sánchez-Bayón, A. (2018). Balance de la Sociología tras la globalización. Eduser, 10, 49-68.

Sánchez-Bayón, A. (2019a). Problemas convergentes de derecho, economía y sociología en la posglobalización. Derecho y Cambio Social, 57, 12-41.

Sánchez-Bayón, A. (2019b). Transición a economía gig. Encuentros multidisciplinares, 21(62), 1-19.

Sánchez-Bayón, A. (2019c). Claves de Derecho de Empresa. Derecho y Cambio Social, 58, 448-66.

Sánchez-Bayón, A. (2019d). Del fin de recursos humanos a la emergencia del talento. Lan Harremanak, 42, 178-96.

Sánchez-Bayón, A. (2019e). Una historia crítica de sociología del trabajo y de las organizaciones. Miscelánea Comillas, 77(151), 431-51.

Sánchez-Bayón, A (2019f). Sociología de la identidad estadounidense. Sindéresis.

Sánchez-Bayón, A. (2019g). Estudio de políticas económicas que aceleran la extinción del Estado de bienestar estatal. Derecho y Cambio Social, 60, 593-605.

Sánchez-Bayón, A., et al (2019). The Spanish B-Schools trouble in digital economy. JEE, 23(5), 1-8.

Schor, J. (2016). Debating the sharing economy. Journal of self-governance and management economics, 4(3), 7-22.

Seligman, M. (2002). Authentic happiness. Free Press.

Seligman, M. (2011). Flourish. Free Press.

Sennett, R. (1998). The Corrosion of Character. Norton.

Taleb, N. (2012). Antifragile. Random House.

Valero, J., Sánchez-Bayón, A. (2018). Balance de la globalización y teoría social de la posglobalización. Dykinson.

VV.AA. (1971). Tras la fachada de las teorías burguesas (trad.). Ed. Progreso.

VV.AA. (1981). Keynes en Harvard. Centro Estudios sobre la Libertad.

VV.AA. (2020). World Economic Outlook: the great lockdown. IMF.

Womack, J., Jones, D., Roos, D. (1990). The machine that changed the World. Free Press.

Womack, J., Jones, D. (2003). Lean thinking. Free Press.

Womack, J., Jones, D. (2014). Lean solutions. Free Press. 